\title{
Experience of a public education programme on early detection of cutaneous malignant melanoma
}

\author{
Valerie R Doherty, Rona M MacKie
}

\begin{abstract}
A public education campaign is described which aimed at encouraging earlier self recognition and thus treatment of cutaneous malignant melanoma. The unique aspect of this campaign was that the changes in the numbers of referrals of patients with melanomas and the changes in the hospital workload associated with this programme were quantified. In the calendar year of the campaign and the following year a statistically significant rise was seen in the percentage of thin melanomas with a good prognosis that were treated and a concomitant significant fall in the proportion of thick lesions with a poor prognosis.
\end{abstract}

\section{Introduction}

The rise in the incidence of cutaneous malignant melanoma is well documented. Data from Scandinavia, Scotland, Australia, New Zealand, and Israel show an average rise in incidence of $7 \%$ a year, equivalent to a doubling over a 10 year period. ' From New Mexico and Arizona there are reports that the incidence of cutaneous melanoma in the so called "Anglo" population has trebled and quadrupled over a decade. ${ }^{2}$ In Scandinavia it has been suggested that if this rate of increase continues malignant melanoma will be commoner than breast cancer by the year 2000 . $^{3}$

It is essential to consider the possibility of prevention of melanoma, or at least its early diagnosis at a curable stage. Melanoma prevention requires that the aetiology is understood, and at present the exact role of ultraviolet light is not certain. Most attention has, therefore, focused on early diagnosis and prompt treatment.

The most important prognostic factor in primary cutaneous melanoma is the Breslow ${ }^{+}$or tumour thickness. In Scotland nearly all (93\%) patients with primary melanomas less than $1.5 \mathrm{~mm}$ thick survive five years after the primary lesion is removed and are apparently tumour free, while the five year survival for patients with tumours that are $1 \cdot 5-3.49 \mathrm{~mm}$ thick is $67 \%$ and for those with tumours thicker than $3.5 \mathrm{~mm}$ it is $31 \%{ }^{5}$

The Clark levels of invasion are alternative prognostic indicators: level 1 , intraepidermal invasion only; 2 , the presence of a few tumour cells in the papillary dermis; 3 , expansion of the papillary dermis by tumour cells; 4 , invasion of the reticular dermis; and 5, invasion of fat.

In Queensland, Australia, which already has one of the highest incidences of melanoma in the world, the incidence is still increasing, but the mortality is rising more slowly than in most other countries. Part of the reason for this may be the success of public education campaigns which have been running for over 20 years. During this time the number of thin melanomas with good prognosis excised has risen sharply. During 1963-9 nearly three quarters of males and two thirds of females had primary tumours invading to Clark levels 3,4 , and $5,{ }^{6}$ whereas by 1977 only half of males and just under half of females had such tumours. Five year survival was reported to have risen from $60 \%$ to $74 \%$ over the period of the study.

Temoshok ${ }^{7}$ reported a significant positive correlation between delay in diagnosis and tumour thickness in superficial spreading melanoma, the histogenetic type which comprises half of primary tumours in most series. In contrast, Cassileth et al failed to find any such relation. ${ }^{8}$ Tumour cell heterogeneity implies that there will be some slowly growing melanomas, probably of the lentigo maligna melanoma subtype which remain thin for a long time, and some rapidly growing thick melanomas, probably of the nodular type. If, however, there is no correlation between delay in diagnosis and tumour thickness then it is difficult to explain the success of the public education campaign in Queensland.

In Scotland during 1979-84 320 (39\%) melanomas were in the tumour thickness category $0-1.49 \mathrm{~mm}, 219$ $(27 \%)$ were $1.5-3.49 \mathrm{~mm}$, and $272(34 \%)$ were $3.50 \mathrm{~mm}$ or greater. ${ }^{5}$ These proportions compared unfavourably with figures from Australia, the United States, and Scandinavia, where half or more of patients had lesions in the range 0-1.49 mm thickness (tables I and II).

In an investigation of 125 patients with melanoma we found that $84 \%$ of Scottish patients delayed seeking medical advice for over three months after noticing a new or changing cutaneous pigmented lesion and that little delay was caused by the general practitioner or the hospital service. ${ }^{13}$ We therefore organised an education campaign to alert the public to the features of early malignant melanoma and to encourage them to seek medical advice promptly, which we predicted would lead to the excision of a higher proportion of thin tumours with a good prognosis and thus in time to an improved survival rate.

This paper describes our experience with the public education campaign on melanoma in the west of Scotland.

\section{Preparing for the public education campaign} DOCTORS AND OTHER HEALTH WORKERS

The results of our earlier survey had shown that general practitioners in the west of Scotland were recognising possible early malignant melanomas and rapidly referring such patients to specialists. In a questionnaire, however, which was sent to a representative sample of 100 local general practitioners, 62 of the 70 who replied stated that they would welcome a public education campaign and felt able to cope with the possible increase in workload that might result. Fifty requested updated information on the management of melanoma, a reminder of the clinical features of early lesions, and information on prognostic features. Therefore a six month professional update period for general practitioners and other members of the primary health care team was planned to take place before the public education campaign of intensive publicity in the second week of June 1985 (Melanoma Week). This is a time of the year in Scotland when some sunshine can be expected and is one month before the traditional west of Scotland holiday period. We expected that the public would be more likely to examine their skin with care at this time of year than in, for example, November.

For the health professionals a booklet with colour illustrations showing the features of early malignant melanoma was prepared, reviewed for suitability of content by a panel of local general practitioners, and mailed by the health board to all general practitioners in the Greater Glasgow Health Board area. A reply paid postcard was enclosed on which the doctor could request a companion booklet on benign pigmented 
naevi (moles), a set of problem solving exercises on managing patients with a range of pigmented lesions, and the use of an educational video on melanoma also specifically prepared for the campaign.

TABLE I-Number (and percentage) of patients with primary melanomas in thickness categories: $0-1.49 \mathrm{~mm}, 1.5-3.49 \mathrm{~mm}$, and over $3.5 \mathrm{~mm}$ in different geographical areas

\begin{tabular}{|c|c|c|c|c|}
\hline Area and year of report & $\begin{array}{l}\text { Total No } \\
\text { studied }\end{array}$ & $\begin{array}{c}\text { Thin: } \\
0.1 \cdot 49 \mathrm{~mm}\end{array}$ & $\begin{array}{l}\text { Intermediate: } \\
1.5-3.49 \mathrm{~mm}\end{array}$ & $\begin{array}{l}\text { Thick: } \\
3.5 \mathrm{~mm}+\end{array}$ \\
\hline New York, $1987^{9}$ & 878 & $527(60)$ & $237(27)$ & $114(13)$ \\
\hline Sydney and Melbourne, Australia, $1985^{111}$ & 2356 & $1272(54)$ & $825(35)$ & $259\left(11^{\star}\right)$ \\
\hline Washington, DC $1979^{11}$ & 138 & $81(59)$ & $32(23)$ & $25(18)$ \\
\hline Sweden, $1985^{12}$ & 572 & $286(50)$ & $212(37)$ & $74\left(13^{\star}\right)$ \\
\hline
\end{tabular}

*In these series the breakpoint between intermediate and thick groups is $3.99 \mathrm{~mm}$.

TABLE II-Incidence of melanoma in the west of Scotland by thickness of lesion (Figures are numbers with percentages in parentheses)

\begin{tabular}{|c|c|c|c|c|c|}
\hline Year & $\begin{array}{l}\text { Total No of } \\
\text { melanomas }\end{array}$ & $\begin{array}{l}\% \text { Increase } \\
\text { from } \\
\text { previousyear }\end{array}$ & $\begin{array}{c}\text { Thin: } \\
0-1.49 \mathrm{~mm}\end{array}$ & $\begin{array}{c}\text { Inter- } \\
\text { mediate: } \\
1 \cdot 5-3.49 \mathrm{~mm}\end{array}$ & $\begin{array}{l}\text { Thick: } \\
3.50 \mathrm{~mm} \ddagger\end{array}$ \\
\hline 1979 & 124 & & $50(40)$ & 3427 & $40(33)$ \\
\hline 1980 & 132 & 6 & $52(39)$ & $34(26)$ & $46(35)$ \\
\hline 1981 & 123 & -7 & $43(35)$ & $35(28$ & $45(37)$ \\
\hline 1982 & 120 & -2 & $46(38)$ & $29(24)$ & $45(36)$ \\
\hline 1983 & 154 & 28 & $60(39)$ & $45(29)$ & $+9(32)$ \\
\hline 1984 & 158 & 3 & $69(44)$ & $42(26)$ & $47(30)$ \\
\hline 1985 & 195 & 23 & $10152)$ & $48(24)$ & $46(24)$ \\
\hline 1986 & 230 & 18 & $120(52$ & $52(23)$ & $58(25)$ \\
\hline
\end{tabular}

Note: Percentages have been rounded to total $100 \%$ in some cases. Percentage of thin lesions 1985 and $1986 v 1979-84: \%^{2}=14 \cdot 01, \mathrm{p}<0 \cdot 005$ $95 \%$ confidence intervals 4.6 to 20 .

During February to May 1985 seven lunchtime and evening meetings were held in postgraduate centres and large health centres throughout the city. More than 300 of the 650 general practitioners on the Glasgow medical list attended these meetings. Five meetings held for nurses working in primary care teams were well attended by enthusiastic groups of nurses.

We also reminded general practitioners of the existence of the weekly pigmented lesion clinic at the Western Infirmary. Patients can be referred to this clinic by phone or letter. If there is concern about the presence of a melanoma patients are seen within the week, and treatment is carried out or arranged before the patient leaves the clinic. All patients who are referred to this clinic are seen within three weeks of referral. The health board sent a notice reminding general practitioners of these arrangements. We hoped to channel most of the increase in hospital workload to this clinic.

\section{PUBLIC EDUCATION MATERIAL}

With the help of the health education department of the Greater Glasgow Health Board informative but non-alarming posters and leaflets on malignant melanoma and how to recognise it at an early stage were designed to be displayed in doctors' surgeries, child health clinics, public libraries, and other public places. A representative sample of patients who were attending both the pigmented lesion clinic and the general dermatology clinic participated in a pilot study to establish whether or not the information conveyed the appropriate message, and minor adjustments were made after their comments were received. Both the poster and the leaflet had the seven point checklist, which is of value in differentiating early malignant melanoma from benign pigmented cutaneous lesions.

(1) Minor itch or other change in sensation in the pigmented lesion.

(2) A lesion greater than $1 \mathrm{~cm}$ in largest diameter.

(3) A history of growth or other change in a pigmented lesion in an adult.

(4) An irregular outline to the pigmented lesion.
(5) Irregular and varied colours within the lesionshades of brown mixed with black, blues, and greys.

(6) Inflammation either at the edge of the lesion or in the lesion.

(7) Bleeding or crusting.

This list is similar to the five ABCDEs of melanoma used by the American Cancer Society in their melanoma education material: asymmetry, border, colour, diameter, and elevation.

In addition to the illustrated material a press release was prepared for circulation to the local and national press and radio and television in the last week of May requesting maximum publicity during the second week in June (Melanoma Week).

\section{Measuring the results of public education}

Our main interest lay in measuring changes in the numbers of patients with melanomas referred for treatment and in the tumour thickness of melanomas treated after the campaign compared with those treated before the campaign. We also planned to measure changes in the numbers of patients with pigmented lesions that were not melanomas who were referred as a result of the campaign. We expected that initially larger numbers of patients with melanomas of all thicknesses might be seen but that over time the proportion with thick tumours would fall and the proportion with thin lesions with a good prognosis would rise. The existing figures on incidence and tumour thickness for 1979-84 (before the campaign) would allow us to interpret any changes during the year of the campaign and subsequent years in the light of previous trends. As the numbers of melanomas and figures on tumour thickness were also available for the Lothian region (Edinburgh and the surrounding area) we planned to use this as a control area which would not receive intense publicity.

We expected that the publicity would result in patients consulting their general practitioners about benign pigmented lesions that were not melanomas. We predicted that a proportion of these patients would be referred to a variety of general dermatological clinics for clinical diagnosis and then in some cases for excision biopsy either for diagnosis or for cosmetic reasons. We therefore counted the numbers of all pigmented cutaneous lesions, including melanomas, seen at the dermatology clinics of the five teaching hospitals in Glasgow in the months of June and July in 1984 (precampaign) and 1985 (campaign year). As most of these referrals for non-melanoma lesions generated by the campaign were channelled through the pigmented lesion clinic we also analysed the total numbers of and the diagnoses for all patients referred to the pigmented lesion clinic in the years 1984, 1985, and 1986. Thus we aimed at quantifying the increased dermatological workload for non-melanomas generated by such a campaign and obtaining an idea of the ratio of non-melanoma pigmented lesions referred to melanomas identified. We also wished to quantify the effect of public education on minor surgery and on the subsequent workload in the pathology departments and therefore measured changes in the numbers of pigmented lesions removed in skin biopsy sessions and the numbers removed in general surgery and in outpatient sessions for plastic surgery. This was done by counting all specimens which were histologically diagnosed as melanocytic naevi, basal cell papillomas (also called seborrhoeic keratoses), basal cell carcinomas, dermatofibromas, and vascular lesions referred to the pathology departments of the five Glasgow teaching hospitals in 1984, 1985, and 1986. We and others recognise that these lesions most often cause confusion in the clinical differentiation of malignant melanoma from non-melanoma cutaneous 
pigmented lesions. Pathology request forms were scrutinised and note taken of the numbers that mentioned melanoma as a possible differential diagnosis.

\section{Results}

Table II gives the numbers of melanomas seen and their distribution between the three thickness categories in the west of Scotland during 1979-86. During 1985 , the campaign year, there was a rise of $23 \%$ in the total number of melanomas diagnosed compared with 1984 , and $101 / 195(52 \%)$ of these were less than $1.5 \mathrm{~mm}$ thick compared with $69 / 158(44 \%)$ in 1984 . In 1986 there was a further rise of $18 \%$ in the total number of melanomas diagnosed, and the distribution between the three thickness categories was similar to that in 1985. The difference in distribution between the three thickness categories in the years 1985 and 1986 is significant compared with that in the preceding years 1979-84.

The interest aroused by the press release and the subsequent publicity was far beyond our expectations. In the four weeks after Melanoma Week information on the campaign was disseminated in 18 television and radio broadcasts and 12 newspapers. No formal news agency search was conducted, so we may have underestimated the impact. Information spread far beyond the west of Scotland with coverage on the national television news and also on Yorkshire Television and in the Coventry Evening Herald. The effect on referrals to our pigmented lesion clinic was seen within two weeks, as the number of new patients quadrupled from 15 to 60 per clinic. From December 1985 to November 1986759 new referrals were made to the clinic compared with 573 for the previous year and 160 for the year before that.

The first self recognised melanoma was excised within four days of the 24 year old patient reading an article in one of the major Scottish daily papers. Increased numbers of patients with both melanoma and non-melanoma pigmented lesions were also referred to the general dermatology outpatient clinics throughout Glasgow, but changes in the absolute numbers referred and the percentage increase were less pronounced. For example, in June and July 1984 there were 171 new referrals for non-melanoma pigmented lesions to general clinics and in June and July 1985266 new referrals. Referrals to the pigmented lesion clinic were 40 and 151 respectively.

Table III shows that in 1985 there was a $13 \%$ increase in the total number of excisions of nonmelanoma pigmented lesions compared with 1984 , the largest percentage increases being for seborrhoeic keratoses and benign naevi. The numbers of basal cell carcinomas and vascular lesions excised during 1985, the campaign year, fell. In 1986, the year after the campaign, the figures are similar to those for 1985 . This may be because although no additional publicity was sought after the second week in June 1985, some material was rerun, thus giving an unexpected boost to public interest. This was particularly noticeable when an interview on "Woman's Hour" was rebroadcast. The period of publicity was extended by many

TABLE III-Number and percentage increase of pigmented lesions excised in Glasgow, 1984-6

\begin{tabular}{|c|c|c|c|c|c|}
\hline Type of lesion & 1984 & 1985 & $\%$ Increase* & 1986 & $\%$ Increase ${ }^{*}$ \\
\hline Naevi & 1128 & $13+1$ & 19 & 1392 & 4 \\
\hline Basal cell carcinoma & 1273 & 1192 & -6 & 1229 & 3 \\
\hline Seborrhoeic keratosis & 573 & 893 & 56 & 800 & -10 \\
\hline Dermatofibroma & 171 & 204 & 19 & 240 & 18 \\
\hline Vascular & 211 & 173 & -20 & 156 & -10 \\
\hline Total & 3356 & 3803 & 13 & 3817 & 3 \\
\hline
\end{tabular}

monthly magazines carrying articles on skin cancer in general and our campaign in particular six to nine months later. Considerable coincidental publicity was given to President Reagan's basal cell carcinoma which was excised in July 1985-one month after our campaign began. Patients who came to the pigmented lesion clinic were asked if they were attending as a result of the public education campaign. Two thirds had sought the advice of their family doctor after seeing campaign publicity, and $80 \%$ of these had seen publicity on television.

We had hoped that the Lothian area could be used as a control. But although no posters or leaflets had been distributed in that area, the radio, television, and newspaper coverage had been just as effective, and two thirds of patients with all types of pigmented lesions who attended dermatology clinics in Edinburgh said that they had sought advice as a result of the campaign.

\section{Discussion}

Our results show an encouraging rise in the percentage of all patients treated for melanoma with thin tumours with a good prognosis and a fall in the percentage of patients with tumours thicker than $3.5 \mathrm{~mm}$. Longer term studies will show if this is associated with a fall in mortality from melanoma. An unavoidable effect of a public education campaign is the increased workload in treating patients with nonmelanoma pigmented lesions. Malignant melanoma cannot be clinically diagnosed with certainty even by an expert, and no general practitioner has a large experience of melanoma.

Throughout the campaign we saw 40 non-melanoma pigmented lesions for every melanoma, which suggests that our family doctors selected patients for referral with a fair degree of skill. The comparable figure in the United States from the skin cancer advice days and fairs recently organised by the American Academy of Dermatology is 1 in 253. ${ }^{1+}$ The American patients, however, are not screened by a primary health care practitioner. This highlights the valuable screening carried out by family doctors in the west of Scotland.

Not all patients with non-melanoma pigmented lesions seen during this campaign were unnecessary referrals. Some melanomas arise in pre-existing naevi, the proportion of melanomas varying from $30 \%$ to $70 \%$ in different parts of the world. The increased numbers of naevi excised during the campaign and subsequent years may include a proportion of such naevi, and it will be interesting to follow up through the Scottish Melanoma Group's pathological data the number of melanomas considered to arise on pre-existing naevi. A falling number would be an encouraging sign that potentially premalignant dysplastic naevi had been identified and removed. During this campaign we also identified and are following up in the pigmented lesion clinic several families and individuals who have dysplastic naevi and thus an increased risk of developing melanoma.

The great interest that was generated by the media campaign was impossible to foresee. Had a major political event occurred during the second week in June 1985 radio, television, and newspaper coverage might have been very limited. Media campaigns need to be planned to avoid foreseeable competition such as the run up to a general election, but there will always be the chance of competition from immediately exciting news around the time planned to launch such activities.

Although most of the patients sought medical advice as a result of television publicity, leaflets and posters were mentioned as the initial stimulus by some patients who self diagnosed their early melanomas. Leaflets are valuable in educating patients about which features of a new or changing pigmented lesion should cause concern. 
Although in our experience television is the best method of putting over a public health education message, in the United States local newspapers are reported to be most effective. ${ }^{15} 16$ This may reflect the fact that many television channels are available to the American viewer, and as cable television spreads in the UK the balance may shift.

Because of the rapid spread of information from the west of Scotland to other parts of the country it was impossible to have a control group that was not exposed to the information. It is advisable therefore to have, as we did, data from preceding years on patients to be used as an internal control. Although the effect of such publicity on the workload in other parts of the country may have been appreciable, it was difficult to predict because of patchy and unexpected interest in areas distant from the west of Scotland and the rerunning of national radio and television programmes.

Throughout we found reporters and journalists, almost without exception, willing to have copy checked for factual accuracy before use. Copy for titles and bylines of articles were not always made available and were occasionally more dramatic and alarming than appropriate.

Seven other centres in the UK have now run similar campaigns for early detection of melanoma funded by the Cancer Research Campaign. It will be interesting to compare their experiences with ours.

We thank the Camilla Samuels Fund for financial support, Dr Doherty, the Imperial Cancer Research Fund for financial help with posters and booklets, and the Scottish Melanoma Group, funded by Scottish Home and Health Department grant No K/MRS/50/C363, for access to data. Mrs Doreen
Watson of the Greater Glasgow Health Education Group offered valuable advice and help. Throughout this study full cooperation was given by the dermatologists, pathologists, and plastic surgeons in Glasgow and Edinburgh, whom we thank.

1 Swerdlow AJ. Epidemiology of cutaneous malignant melanoma. In: MacKie RM, ed. Clinics in Oncology. Melanoma. Vol 3, No 3. London: Saunders, 1984:407-37.

2 Schreiber MM, Bozzo PD, Moon TE. Malignant melanoma in southern Arizona. Arch Dermatol 1981;117:6-11.

3 Kopf AW, Kripke ML, Stern RS. Sun and melanoma. 7 Am Acad Dermatol 1984;11:674-84.

4 Breslow A. Thickness, cross-sectional area and depth of invasion in the prognosis of cutaneous melanoma. Ann Surg 1970;172:902-8.

5 MacKie RM, Soutar DS, Watson ACH, et al. Malignant melanoma in Scotland 1979-1983. Lancet 1985; ii:859-62.

6 McLeod GR. Control of melanoma in high-risk populations. In: Elwood JM Melanoma and naevi. Pigment Cell. Vol 9. Basel: Karger, 1988:133.

7 Temoshok L, Di Clemente RJ, Sweet DM, Blois MS, Sagebiel RW. Factors related to patient delay in seeking medical attention for cutaneous malignant melanoma Cancer 1984:54:3048-53.

8 Cassileth BR, Clark WH Jr, Heiberger RM, March V, Tenaglia A. Relationship between patients' early recognition of melanoma and depth of invasion. ship between patients' early

9 Kopf AW, Gross DF, Rogers GS, et al. Prognostic index for malignant melanoma. Cancer 1987;59:1236-41.

10 Urist MM, Balch CM, Soong S, Shaw HM, Milton GW, Maddox WA. The influence of surgical margins and prognostic factors predicting the risk of local recurrence in 3445 patients with primary cutaneous melanoma. Cancer $1985 ; 55: 1398-402$

11 Breslow A. Prognostic factors in the treatment of cutaneous melanoma J Cutan Pathol 1978;6:208-12.

12 Eldh J, Boeryd B, Suurkula M, et al. Melanoma in Sweden: experience at the University of Goteborg. In: Balch CM, Milton GW, eds. Cutaneous melanoma. Philadelphia: Lippincott, 1985:473.

13 Doherty VR, MacKie RM. Reasons for poor prognosis in British patients with cutaneous malignant melanoma. BrMed 7 1986;292:987-9.

14 Arundell FD. Screening for melanoma and skin cancer FAMA 1986-255: 3443

15 Field SI. Melanoma/skin cancer screening in Michigan. 7 Am Acad Dermatol 1987; 16:578-83.

16 Olsen TG, Feeser TA, Conte ET, Schroeter AL. Skin cancer screeninglocal experience. 7 Am Acad Dermatol 1987; 16:637-41.

Accepted 25 May 1988)

\section{Department of \\ Epidemiology, London \\ School of Hygiene and \\ Tropical Medicine, \\ London WC1E 7HT \\ Adèle Green, PHD, research \\ fellow \\ Valerie Beral, MRCP, reader \\ Social Statistics Research \\ Unit, City University, \\ London ECIV OHB \\ Kath Moser, MSC, research \\ fellow}

Correspondence to:

Dr Beral.

\title{
Mortality in women in relation to their childbearing history
}

\author{
Adèle Green, Valerie Beral, Kath Moser
}

\begin{abstract}
With data from the Office of Population Censuses and Surveys' longitudinal study the mortality of currently married women aged under 60 in 1971 was investigated in relation to the number of liveborn children reported at the 1971 census, adjusting for their husbands' social class. Women who had never had children experienced a higher mortality from many causes of death than the parous women, and this was probably due, at least in part, to selective factors. When the analysis was confined to parous women mortality from diabetes mellitus and cervical cancer increased significantly and oesophageal cancer decreased significantly with increasing number of liveborn children. Mortality from all circulatory diseases and from hypertensive disease, ischaemic heart disease, and subarachnoid haemorrhage tended to rise with parity, though the trends were not statistically significant. Mortality from breast cancer decreased significantly with the number of liveborn children, but only when nullipara were included in the analyses.
\end{abstract}

These data suggest that there may be residual and cumulative effects of childbearing which influence patterns of disease in the long term.

\section{Introduction}

The relation between a history of childbearing and women's health in the long term has been little studied, except for cancers of the reproductive organs. The risk of breast, ovarian, and endometrial cancers is lower and the risk of cervical cancer higher in women of high parity than in nulliparous women..$^{1-3}$ It has been suggested that the risk of gastric ${ }^{13}$ and possibly brain ${ }^{2}$ cancer may increase with the number of children a woman has had, but few studies have investigated these relations. The evidence about cancer of the colon is conflicting, some researchers reporting a decreasing risk with increasing parity ${ }^{45}$ and others finding no relation. ${ }^{26}$

Among married women the parous have been found to experience an excess mortality from ischaemic heart disease, nephritis and nephrosis, diabetes mellitus, and cerebrovascular disease compared with the nulliparous. ${ }^{3}$ Findings from case-control studies of women with coronary heart disease ${ }^{78}$ and diabetes mellitus ${ }^{9}$ suggest that the relative risk of each condition increases with the number of children a woman has had, but these findings are from small studies of selected women

There are no data which systematically relate women's reproductive history to their long term health. Furthermore, some of the associations described might be confounded by socioeconomic class. For example, the association between stomach cancer or ischaemic heart disease and high parity might be because these conditions and high parity are more common in the lower social classes; and the association between breast, ovarian, or endometrial cancer and nulliparity might be because those conditions and nulliparity are more common in the higher social classes. ${ }^{10}$ 